\title{
Effects of duct ligation and orchidectomy on histochemical reactions in the hamster epididymis*
}

\author{
K. A. Moniem†, T. D. Glover and C. W. Lubicz-Nawrockił \\ $\dagger$ Department of Veterinary Anatomy, P.O. Box 32, Khartoum North, Sudan, and \\ Reproductive Biology Group, Department of Veterinary Anatomy, University of \\ Queensland, St Lucia, Queensland, Australia
}

\begin{abstract}
Summary. The epididymis was ligated at the efferent ductules and at the middle segment. Histochemical changes occurred only proximal to the ligature. Orchidectomy caused progressive changes, mostly reversible by testosterone treatment, throughout the epididymis. It is concluded that the integrity of the initial segment is dependent upon androgen reaching it via the testicular fluid.
\end{abstract}

\section{Introduction}

Ligation of the efferent ductules of the testis does not impair the transport of spermatozoa through the epididymis, and it might therefore be assumed that the procedure exerts no influence on epididymal function generally. However, the evidence is conflicting. Separation of the testis from the epididymis apparently causes no change in epididymal histology in the rat (Turner \& Johnson, 1971), but histological changes are discernible in proximal regions of the epididymis in ruminants (Gustaffson, 1966).

Cytological changes have not been clearly demonstrated after occlusion of the epididymis, although in rabbits the epithelial cells lining the duct become flattened above the site of occlusion (Glover, 1962) and regressive changes in the incarcerated spermatozoa are well documented (Glover, 1962; Orgebin-Crist, 1969; Paufler \& Foote, 1969). The effect of epididymal ligation on the function of the lining epithelium will presumably differ from that of efferent ductule ligation, because in the former case spermatozoa, together with rete testis fluid and its contained androgen, will continue to enter the duct, whilst in the other they are prevented from doing so. This means that efferent ductule ligation deprives the lining cells of testicular androgen even though, in spite of reduced capillary blood flow (Brown \& Waites, 1972), there should be a supply of steroid from the circulation. On these grounds, it seemed reasonable to extend our initial investigation into the effects of duct ligation on the epididymal cells by testing also the effect of total androgen withdrawal (caused by orchidectomy) and steroid replacement treatment.

\section{Materials and Methods}

All the experiments were carried out with golden hamsters (Mesocricetus auratus) and the terminology used to indicate different regions of the epididymis (Text-fig. 1) is based on that suggested by Glover \& Nicander (1971). The animals were anaesthetized with sodium pentobarbitone for all operations.

Ligation. In Group 1 the efferent ductules of 4 hamsters were ligated bilaterally (site A in Text-fig. 1) and the animals were examined 8 weeks later when the spermatozoa had been transported into the terminal segment of the epididymis. In Group 2, both epididymides of 16 animals were ligated, approximately at the junction of the middle and terminal segments (site $B$ in Text-fig. 1). These

\footnotetext{
* Reprint requests to Professor T. D. Glover, Department of Veterinary Anatomy, University of Queensland, St Lucia, Queensland, Australia.

$\ddagger$ Present address: Instituto de Biologia y Medicina, Experimental Laboratorio de Esteroides, Obligado 2490, 1428 Buenos Aires, Cap. Fed., Argentina.
} 
animals were killed $2,7,14$ or 28 days after ligation (4/group). Because histochemica. reactions in the normal intact epididymis of the hamster have already been described (Moniem \& Glover, 1972), no further control material was provided; the control material illustrated here is taken directly from previous work for comparison.

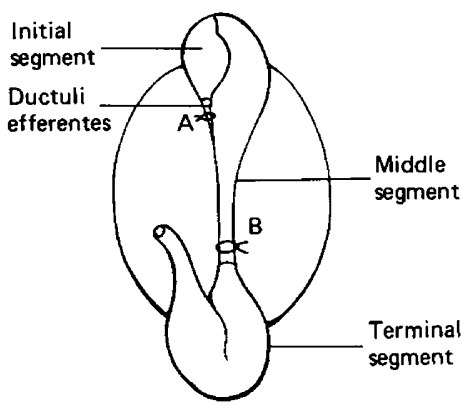

Text-fig. 1. Diagram of the different parts of the hamster epididymis showing the sites of ligation (A and B) and study.

Orchidectomy. Hamsters were bilaterally castrated and 4 animals were killed on each of Days $1,4,7,21$ and 28 after the operation. Castrates (4) in a 6th group were given a subcutaneous implant of $25 \mathrm{mg}$ testosterone propionate (Organon Laboratories) and were killed after 1 month.

The epididymal and testicular tissues were prepared for histological and histochemical staining, i.e. haematoxylin and eosin, PAS-reactive substances, RNA, phosphatases, $\beta$-glucuronidase and lactate and succinate dehydrogenases. The methods employed and their rationale were those used previously (Moniem \& Glover, 1972).

\section{Efferent ductule ligation}

\section{Results}

Ligation of the efferent ductules resulted in signs of regression in the initial segment and in the proximal part of the middle segment; there was a reduction in epithelial cell height, a marked reduction in the diameter of the lumen, virtual absence of RNA (Pl. 1, Figs 1, 2, 3 and 4) and weak activity of lysosomal and oxidative enzymes localized in the tubular epithelium. Activity of lactate dehydrogenase, which is normally strong and localized in the apical part of the epithelial cells, was abolished. The remainder of the epididymis was histochemically unchanged in all the animals. Some PAS-positive material was found throughout the length of the duct, but spermatozoa were present only in the terminal segment. Spermatogenesis was arrested in most of the seminiferous tubules.

\section{Ligation of the epididymal middle segment}

Above the site of ligation, there was a pronounced decrease in the epithelial content of RNA, glucose-6-phosphatase, acid phosphatase, non-specific esterase, $\beta$-glucuronidase, lactate dehydrogenase and succinate dehydrogenase. Alkaline phosphatase, normally localized in the interlobular connective tissue of the epididymis, was eliminated and the intensity of staining for ATPase and AMPase (Pl. 1, Figs 5 and 6) was greatly reduced. These changes first occurred immediately above the site of ligation and then progressed proximally. Effects were not observed in the initial segment until 7 or even, in some animals, 14 days after ligation. After 28 days (and 14 days in some animals) the development of spermatocoeles made observations difficult. Below the site of ligation, the histochemical appearance remained unchanged.

Within 2 days many abnormal spermatozoa appeared immediately above the ligature but did not occur in the initial segment until after Day 14, when degenerate spermatozoa were associated with spermatocoeles. Spermatozoa below the ligature appeared to be unaffected but spermatogenesis was impaired by Day 28, presumably because of the increased pressure from the epididymis. 

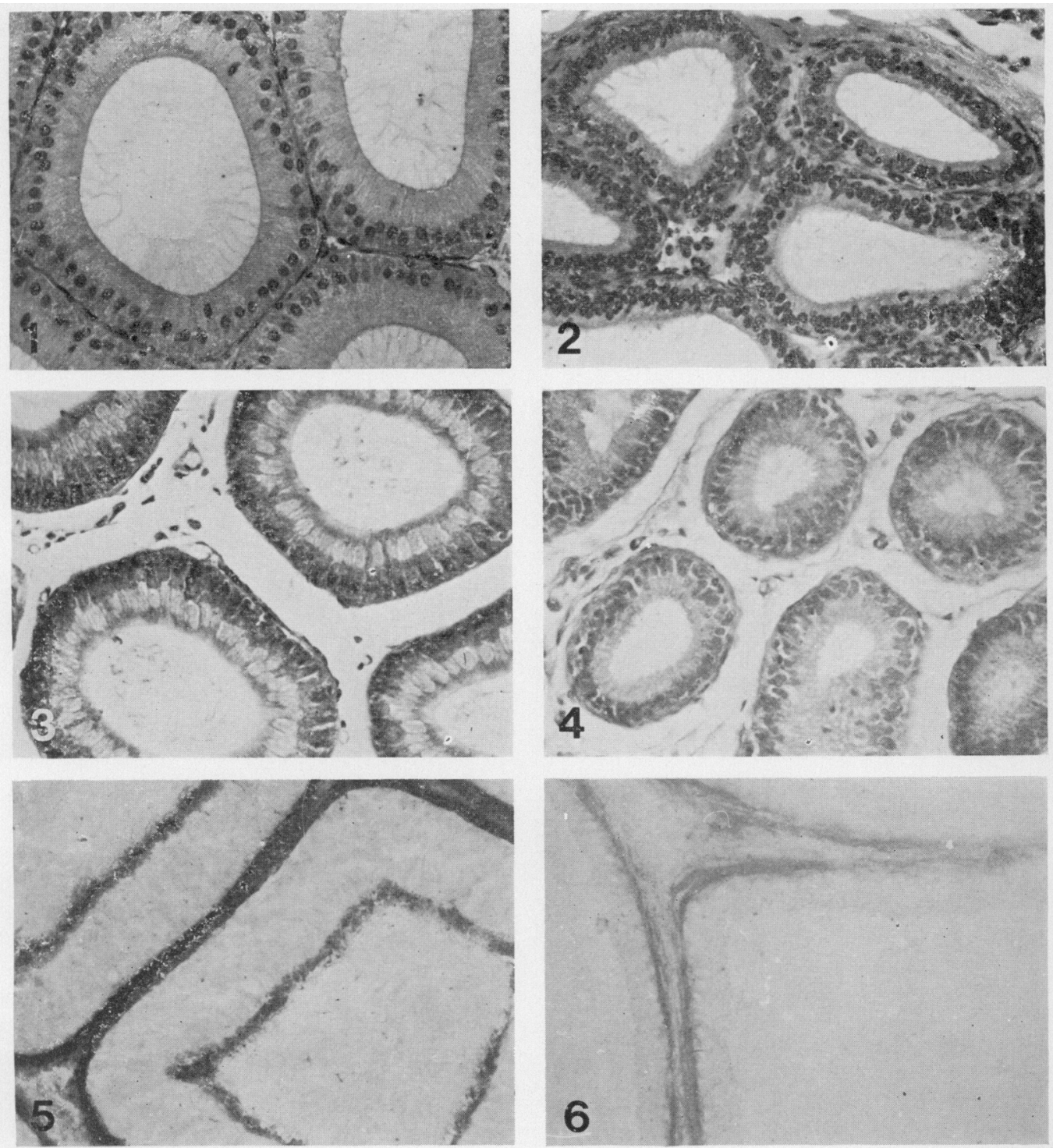

Figs 1 and 2. Tubules of the initial segment of the hamster epididymis. showing the reduction of epithelial cell height 8 weeks after ligation of the efferent ductules (Fig. 2) compared with that in an intact hamster (Fig. 1). Bouin, $\mathrm{H} \& \mathrm{E}, \times 400$.

Figs 3 and 4. Tubules of the initial segment stained for RNA activity. Fig. 3. An intact epidjdymis and a typical histochemical reaction. Fig. 4. The reduced reaction 8 weeks after efferent ductule ligation. AFA. methyl green-pyronin, $\times 400$.

Figs 5 and 6. Reaction of adenosine monophosphatase in the middle segment of the hamster epididymis. intact (Fig. 5), and 7 days after ligation of the middle segment (Fig. 6). showing the lack of reaction in the stereocilia and the reduced activity in the intertubular connective tissue. Lead nitrate method. $5 \mathrm{~min}$ incuhation. $\times 400$. 

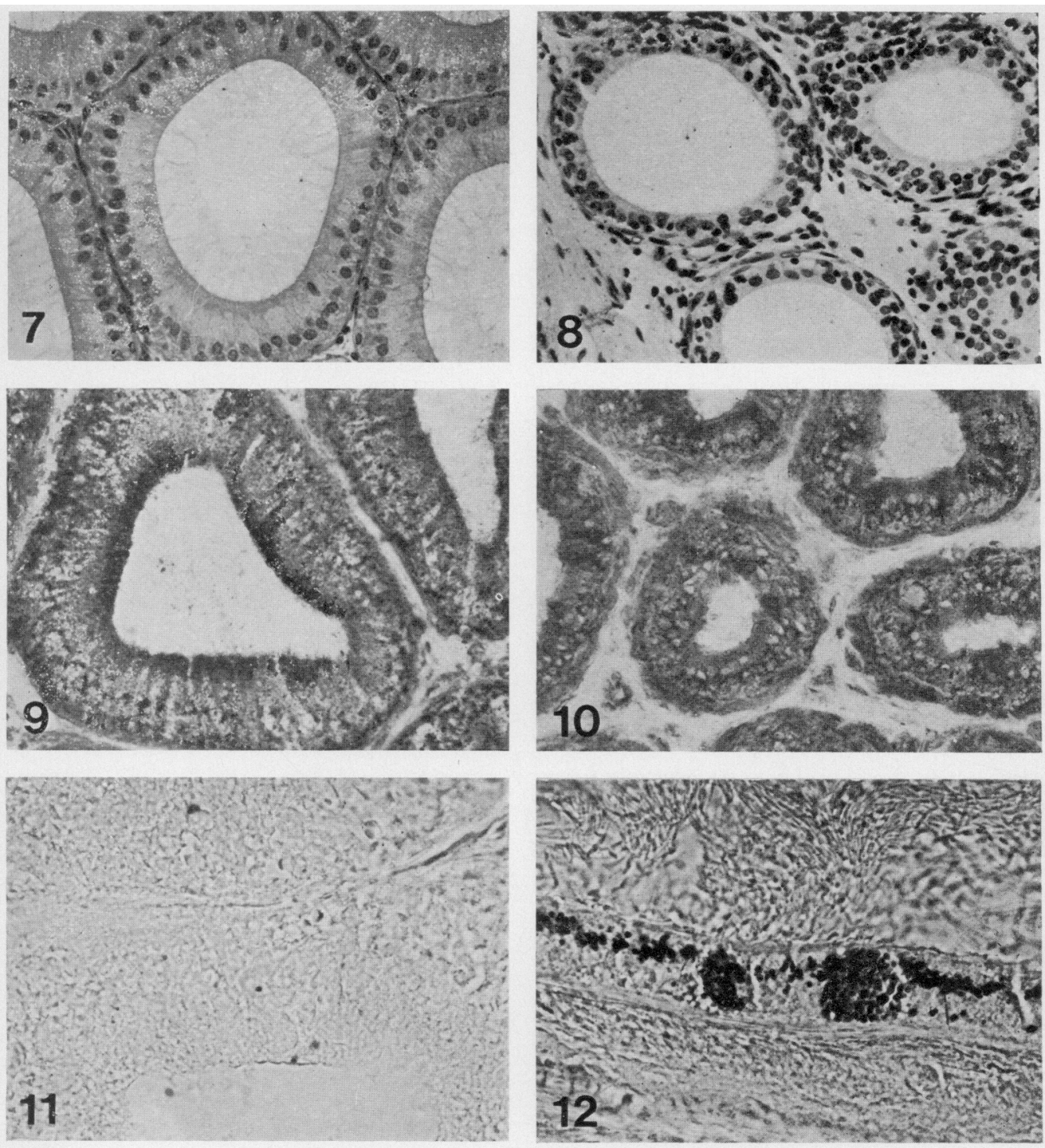

Figs 7 and 8. The initial segment of the epididymis of an intact hamster (Fig. 7) and one bilaterally cas!rated 4 days before (Fig. 8). The epithelial cell height is reduced after castration. Bouin, H \& E, $\times 400$.

Figs 9 and 10. The activity of lactate dehydrogenase in the initial segement of an intact hamster (Fig. 9) and one killed 7 days after bilateral castration (Fig. 10). The apical reaction has been abolished and the general cytoplasnic reaction reduced. Nitroblue tetrazolium. 5 min incubation. $\times 400$.

Fig. 11. Acid phosphatase activity in the initial segment 7 days after bilateral castration. Note the virtual absence of reactive granules. Lead nitrate method. $30 \mathrm{~min}$ incubation. $\times 1000$.

Fig. 12. Normal acid phosphatase activity in the terminal segment 7 days after hilateral castration. Lead nitrate method. 10 min incubation. $\times 1000$. 


\section{Orchidectomy}

The epithelial lining of the initial segment proved to be more sensitive to the absence of the testis than that of any other part of the epididymis. By Day 1 after castration, there was a reduction of RNA and acid phosphatase in the initial segment and by Day 4 epithelial cell height and lumen diameter were also reduced and the nuclei of the cells were pyknotic (PI. 2, Figs 7 and 8 ). The activity of $\beta$ glucuronidase was weak and PAS-positive material in the supranuclear cytoplasm and stereocilia was reduced.

These changes extended progressively to more distal levels of the epididymis, and after 14 days the changes in the initial segment were more pronounced and the whole of the ductus epididymidis showed similar signs of degeneration. There was some thickening of subepithelial connective tissue throughout the duct and it was strongly PAS-positive, but the normally intense reaction of hydrolytic enzymes in the proximal limb of the terminal segment and the intensity of staining for lactate dehydrogenase (PI. 2, Figs 9 and 10) and succinate dehydrogenase were noticeably decreased. The reaction of phosphatases was capricious and sometimes difficult to interpret, but acid phosphatase disappeared from the initial segment at a time when it was still active in the terminal segment (Pl. 2, Figs 11 and 12). The distribution of AMPase was also affected in the middle segment of the epididymis. These changes became more conspicuous as time passed and leucocytes began to appear in the lumen by 21 and 28 days after castration.

All of these histochemical changes, except those in the initial segment and proximal part of the middle segment were prevented by testosterone treatment. Castration changes in the lining cells of these parts of the epididymis were relatively unaffected by exogenous androgen, even when graded doses of testosterone propionate between 100 and $400 \mu \mathrm{g}$ were administered subcutaneously.

\section{Discussion}

The present results give support to the suggestion of Gustaffson (1966) that the upper part of the epididymis, especially the initial segment, depends for its normal function upon having a patent channel of communication with the testis via the ductuli efferentes. It is now well known that tubular androgen from the testis and androgen-binding protein are normally taken to the cells of the initial segment (see Setchell, 1970). Our results suggest that some component of the tubular fluid is crucial to the normal function of the cells of the initial segment and it seems likely that this component is an androgen. If this is true, then the cells of the initial segment of the epididymis require tubular androgen as well as circulating androgen to maintain their normal function. In contrast, cells lining the terminal segment of the epididymis appear to be adequately served by circulating androgen alone. Early disorders of the cells of the initial segment, as distinct from those of the terminal segment, following efferent ductule ligation provide strong evidence for this view. It is also evident that the lining cells of the initial and middle segments only function properly when the duct itself is patent. Ligation of the epididymis rapidly results in disturbed function of the cells above the site of occlusion.

This work, which was begun in Liverpool and completed elsewhere, was supported by grants from the Ford Foundation and the British Council. Our thanks are also due to the Government of the Sudan for its support to one of us (K.A.M.).

\section{References}

BRoWN, P.D.C. \& WAITES, G.M.H. (1972) Regional blood flow in the epididymis of the rat and rabbit: effect of duct ligation and orchidectomy. $J$. Reprod. Fert. 28, 221-223.

Glover, T.D. (1962) The response of rabbit spermatozoa to artificial cryptorchidism and ligation of the epididymis. J. Encdor. 23, 317-328.
Glover, T.D. \& NiCANDER, L. (1971) Some aspects of structure and function in the mammalian epididymis. J. Reprod. Fert., Suppl. 13, 39-50.

GustafFson, B. (1966) Luminal content of the bovine epididymis under conditions of reduced spermatogenesis, terminal blockage and certain sperm abnormalities. Acta vet. scand., Suppl. 17, 5-80. 
MONIEM, K.A. \& Glover, T.D. (1972) Comparative histochemical localization of lysosomal enzymes in mammalian epididymides. J. Anat. 111, 437-452.

OrGEBIN-CRIST, M.C. (1969) Studies on the function of the epididymis. Biol. Reprod., Suppl. 1, 155-175.

Paufler, S.K. \& FoOTE, R.H. (1969) Morphology, motility and fertility of spermatozoa recovered from different areas of ligated rabbit epididymis. J. Reprod. Fert. 17, 125-137.

Setchell, B.P. (1970) Testicular blood supply, lym- phatic drainage and secretion of fluid. In The Testis, vol. 1, pp. 101-239. Eds A. D. Johnson, W. R. Gomes \& N. L. VanDemark. Academic Press, New York.

TURNER, P.C. \& JoHnson, A.D. (1971) Epididymal lipid of the rat with and without testicular contribution. J. Reprod. Fert. 27, 249-255.

Received 13 February 1978 